\section{Digestibilidade (aparente) do farelo de soja e do feno "Coast-Cross" em dietas com diferentes proporções volumoso/concentrado, fornecidas para bovinos}

\author{
Soybean meal and coast cross hay digestibilities with bos \\ taurus fed with different ratios roughage/concentrate in their \\ diets
}

CORAESPONDENCE TO

Cartos de Souza Luco

Departamento de Nutricato e Produçsto Animal

Facutdada de Modicina Veterináns e

Zootecnia da USP

Av. Durque de Carias, 225

Caixa Postal 23

$13680-000$ - Pirassununga - SP .

Brasil

o-mail: terassicusp.br

1 - Departemento de Nutriçåo e Produçāo Animal

Faculdado de Modicina

Veterinária e Zootecnia da USP - SP

Adriana Ramenzoni SEFRIN' ; Carlos de Sousa I.UCCI' ; Laércio MEI.O'T'TI'

\title{
RESUMO
}

O presente trabalho teve por objetivo avaliar a digestibilidade (aparente) do farelo de soja e do feno de "coast-cross" em diferentes proporçōes de volumoso: $A=40 \%$; $B=60 \% ; C=80 \%$; e $D=100 \%$, de feno nas dietas. Os animais utilizados foram 8 bovinos, com peso médio de $200 \mathrm{~kg}$, que permaneceram em gaiolas metabólicas. O periodo de coleta de fezes foi de 7 dias. Os coeficientes médios de digestibilidade foram: $\mathrm{MS}=71,61 \%, 71,43 \%, 60,39 \%$ e $62,61 \% ; \mathrm{PB}=73,32 \%, 78,12 \%, 73,55 \%$ e $74,34 \% ; \mathrm{FB}=59,74 \%, 66.56 \%$, 63.80 e $65,74 \%$; ENN $=75,95 \% 73,94 \%, 58,02 \%$ e $60.93 \%$; EE $=72,90 \%, 70,84 \%, 61,04 \%$ e $63,30 \%$. para os tratamentos A, B. C e $D$, respectivamente. Os valores de NDT foram: $A=63.13 \% ; B=62,20 \% ; C=54,96 \% ;$ e $D=51,28 \%$. As digestibilidades da $M S$, ENN e os valores de NDT aumentaram à medida que a proporção de concentrado era aumentada na raçāo $(P<0,01)$.

UNITERMOS: Digestibilidade, Bovino, Feno, Farelo de soja.

\section{INTRODUÇÃO}

$\mathrm{R}$ obinson: Kennelly'2 (1991), trabalhando com vacas de leite. encontraram maiores digestibilidades da matéria seca (MS) e do nitrogênio não-protéico (NNP) nas fêmeas alimentadas com dietas baixas em volumosos; jả a digestibilidade do nitrogênio não apresentou diferenças significativas entre tratamentos e, ao contrário, a digestibilidade da fração fïbrosa (FDN) mostrou maiores valores na dieta com alto nível de volumoso.

Castro el al. ${ }^{2}(1991)$ forneceram para ovelhas raçīes com niveis de $100 \%$ a $40 \%$ de volumoso, e observaram que. com os valores menores, a digestibilidade da MS aumentou enquanto que a da fibra bruta (FB) diminuiu. Do mesmo modo. P(xore et al." (1990). avaliando niveis desde $70 \%$ a $10 \%$ de volumoso. encontraram redução na digestibilidade da MS com a diminuição dos alimentos grosseiros na ração.

Colucci et al, ' (1989). estudando proporçōes de volumosos de $80 \%$ a $30 \%$, observaram que o aumento do consumo de MS causou diminuição na digestibilidade das diferentes fraçčes da dieta. sendo os resultados mais acentuados na ração com $30 \%$.

Kawas et al. ${ }^{x}(1991)$, avaliando dietas isonitrogenadas com proporçìes de grosseiros entre $75 \%$ a $4.5 \%$, fonecidas para caprinos. encontraram naquelas com menores proporçōes, aumento da digestibilidade da fração FDN e menor ingestão de MS.

D\%hurbinev '"f al, (1989), fornecendo quantidades de $80 \%$ a $42 \%$ de volumosos em raçōes de hovinos, observaram maior ingestão de alimento e maiores digestibilidades da MS e PB com a menor proporção de volumosos. Também Khalili et al." (1992), avaliando dois tipos de feno em ingestão ad libisum juntamente com níveis de suplementaçāo concentrăda $(0,25$ ou $5 \mathrm{Kg} / \mathrm{vaca} / \mathrm{dia})$, encontraram aumento linear na digestibilidade da $\mathrm{MS}$ e $\mathrm{PB}(\mathrm{p}<0,001)$ quando elevaram a quantidade de concentrados. porém. a da fraçào FDN não se alterou. independente da fonte de fíbra utilizada. Os mesmos autores relataram aumento na ingestão de MS total quando usaram maior nível do suplemento concentrado.

Flachowsky; Schneider' (1992), fonecendo para bovinos e ovinos dietas com proporçcóes de volumosos de $80 \%$ a $20 \%$. encontraram diminuição da digestibilidade da fibra quando os animais consumiram ad libitum dictas baixas em alimentos grosseiros. Esses resultados não se repetiram quando a ingestão de alimentos foi permitida apenas para atender às exigências de mantença.

Uden's (1984) observou elevação na digestibilidade da fíbra do feno $(p<0.01)$ à medida que aumentava o teor de volumoso na ração. A digestibilidade de FDN seguiu o mesmo padrão com niveis de $70 \%$ ou mais de volumosos nạ ração.

Este trabalho procura definir melhor a influência de diferentes proporçōes de concentrados (farelo de soja)e volumosos (feno colast(ross). sobre a digestibilidade de diversos alimentos utilizados na ração. com vistas ao arraçoamento mais adequado de bovinos.

\section{MATERIAL E MÉTODO}

O) experimento foi conduzido nas dependências da Faculdade de Medicina Veterinária e Zootecnia - USP. Campus de Pirassununga. São Paulo.

Foram utilizados 8 bovinos de $200 \mathrm{~kg}$ de peso vivo (PV). 
mestiços europeu-zebu, machos castrados, todos providos de fístulas ruminais, que foram adaptados aos alimentos em baias individuais, antes de entrarem nas gaiolas de digestibilidade.

Constituíram-se quatro tratamentos tendo como volumoso o feno de coast-cross (Cynodon dactylon), e como concentrados o grão de milho (Zea mays L.) e o farelo de soja (Glicyne $\max (\mathrm{L}$.$) Merril), sendo \mathrm{A}=40 \%$ de volumoso e $60 \%$ de concentrado, $\mathrm{B}=60 \%$ de volumoso e $40 \%$ de concentrado, $\mathrm{C}=$ $80 \%$ de volumoso, $20 \%$ de concentrado e $\mathrm{D}=100 \%$ de volumoso.

No tratamento D foram ministrados, via fístula ruminal, $80 \mathrm{~g}$ de uréia (diluição $1000 \mathrm{~g}$ de uréia em $2000 \mathrm{ml}$ de água), fornecida duas vezes ao dia adicionando-se concomitantemente $500 \mathrm{~g}$ de melaço e $40 \mathrm{~g}$ de sulfato de cálcio (fonte de enxofre).

A formulação das rações foi realizada segundo as exigências nutricionais recomendadas pelo $\operatorname{NRC}^{10}$ (1989), tornando-se todas isonitrogenadas, sendo farelo de soja e milho em grãos os componentes das misturas concentradas.

Quando os animais já estavam adaptados aos alimentos, foram colocados em 8 gaiolas metabólicas para bovinos, confeccionadas em madeira, obedecendo às dimensões apresentadas por Horn et al. ${ }^{7}$ (1954).

O experimento constou de 3 períodos, sendo o primeiro de adaptação aos novos alimentos com 21 dias de duração, conduzido fora das gaiolas; o segundo, já nas gaiolas, durou 3 dias de adaptação às mesmas; o último período, de 7 dias, compreendeu coleta total de fezes.

Os animais foram pesados no início e no final do período experimental.

Os alimentos eram pesados antes de seu fornecimento. As sobras que porventura ocorriam, não excedendo a $10 \%$ do oferecido, eram moídas e incorporadas na ração.

No período experimental eram colhidas diariamente todas as fezes, pesadas, homogeneizadas em piso cimentado e tomava-se uma amostra de $5 \%$ do total excretado. $O$ método utilizado compreendeu a execução de três períodos: de adaptação ao alimento ( 10 dias), de ajuste ( 7 dias), no qual os animais foram colocados em boxes individuais, e de coleta ou principal (7 dias) quando os animais receberam $80 \%$ do alimento que consumiam ad libitum, parcialmente iniciado já nos últimos 3 dias do período de ajuste. Foi feita a coleta do total das fezes e, da quantidade total de fezes de cada animal, a cada dia retirou-se alíquota de $10 \%$, a qual era depositada em bandeja numerada, uma para cada bovino. O procedimento foi semelhante ao descrito por Schneider; Flatt ${ }^{13}$ (1975).

As amostras de fezes eram pesadas e colocadas em estufa a $65^{\circ} \mathrm{C}$, por 72 horas, para determinação da MS a $65^{\circ} \mathrm{C}$, e, após moídas, encaminhadas ao laboratório para análise bromatológica.

As amostras dos alimentos e das fezes foram analisadas para determinação da MS, PB, EE, FB e MM, segundo o $\mathrm{AOAC}^{\prime}(1980)$. Foi utilizado o delineamento experimental inteiramente casualizado, com 2 repetições por tratamento, segundo Gomes ${ }^{6}$ (1985).

\section{RESULTADOS E DISCUSSÃO}

A composição dos ingredientes das frações utilizadas nos quatro tratamentos encontra-se na Tab. 1.

$\mathrm{O}$ consumo médio diário de alimentos durante o período experimental é mostrado na Tab. 2, em termos de MS de feno, de concentrados e MS total/animal/dia, em MS por $10 \mathrm{~kg}$ de peso e em matéria seca por quilo de peso metabólico (W 0,75 ).

Os coeficientes médios de digestibilidade aparente da MS, PB, FB, ENN e EE, assim como os valores de NDT, constam da Tab. 3, para os diversos tratamentos.

As digestibilidades da matéria seca e dos extrativos não nitrogenados diminuíram com o aumento da proporção de volumoso na ração ( $p<0,01$ ); o valor do NDT, da mesma forma, diminuiu com o aumento de feno $(p<0,01)$. As digestibilidades da proteína e da fibra mostraram diferenças significativas, mas no último caso, o valor encontrado para o tratamento $A$ foi algo menor do que o obtido pelos demais tratamentos.

$\mathrm{O}$ decréscimo linear na digestão de MS $(\mathrm{p}<0,01)$, com o aumento na proporção de volumoso, está de acordo com Dzhurbinev et al. ${ }^{4}$ (1989); Poore et al. "1 (1990); Castro et al. ${ }^{2}$ (1991); Kawas et al. ${ }^{8}$ (1991); Robinson; Kennelly ${ }^{12}$ (1991); Khalili et al. ${ }^{9}$ (1992), o que de certa forma era esperado devido à maior digestão dos alimentos concentrados.

Os valores de digestibilidade do ENN (carboidratos solúveis) e os valores de NDT também apresentaram comportamento semelhante ao da digestão da MS, com diminuição linear ( $p<$ 0,01 ), à medida que se aumentava a fração volumosa na ração; o que está de acordo com as pesquisas de Dzhurbinev et al. ${ }^{4}$ (1989) e Robinson; Kennelly ${ }^{12}$ (1991), onde o aumento dos concentrados na dieta elevou a digestibilidade desses nutrientes.

Quanto aos valores de digestibilidade da PB e da FB, não foram encontradas diferenças significativas na digestibilidade do nitrogênio, porém para estes autores, a digestibilidade da fração FDN diminuiu à medida que decrescia o nível de volumoso na alimentação. Já Poore et al. " (1990) Flachowsky; Schneider ${ }^{5}$ (1992) e Khalili el al. ${ }^{9}$ (1992) não observaram diferenças significativas na digestibilidade da FB.

Khalili et al. ${ }^{9}$ (1992) relataram aumento linear na digestibilidade de ambas MS e PB ( $p<0,001$ ), quando elevou-se a quantidade de concentrado na alimentação.

Problemas surgiram com os tratamentos C e D $(80 \%$ e $100 \%$ de volumosos, respectivamente), onde os animais tiveram dificuldades de adaptação às gaiolas metabólicas, apresentando queda no consumo de matéria seca por dia (Tab. 2)

Udem $^{14}$ (1984), Castro et al. ${ }^{2}$ (1991), Kawas et al. ${ }^{7}$ (1991) e Robinson; Kennelly'2 (1991) observaram decréscimo na digestão da fibra quando diminuíram o nível de alimento volumoso. Uden ${ }^{14}$ (1984) indicou que valores de volumosos inferiores a $70 \%$ já apresentaram diminuição na degradabilidade da fração FDN. Dzhurbinev et al. ${ }^{4}$ (1989) mostraram aumento na digestibilidade da PB com menores quantidades de volumoso na alimentação. 


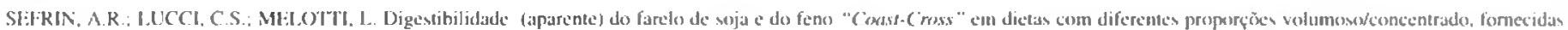

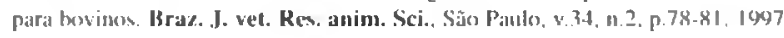

Tabela 1

Composiçōo químico-bromatológica dos ingredientes das raçōes para bovinos em porcentogem, com base na MS. Pirassununga - SP, 1990.

\begin{tabular}{|c|c|c|c|c|}
\hline Ingredientes & Milho & Farelo Soja & Feno & Melaço \\
\hline $\begin{array}{c}\text { MS } \\
P B \\
F B \\
\text { EE } \\
\text { MM } \\
\text { ENN } \\
\text { Ca } \\
P\end{array}$ & $\begin{array}{c}90,40 \\
11,68 \\
3,20 \\
5,31 \\
1,47 \\
78,24 \\
0,09 \\
0,24\end{array}$ & $\begin{array}{c}87,30 \\
53,00 \\
6,19 \\
2,89 \\
2,60 \\
68,52 \\
0,28 \\
0,31\end{array}$ & $\begin{array}{c}86,90 \\
12,29 \\
33.95 \\
2,36 \\
7,71 \\
43,69 \\
0,18 \\
0,25\end{array}$ & $\begin{array}{c}64,76 \\
0,66^{\circ} \\
- \\
- \\
2,15 \\
97,19 \\
-- \\
-\end{array}$ \\
\hline
\end{tabular}

*Uréia Petrofértil (Nitrogênio Total mínimo $=45 \%$ )

MS = Matéria seca

$\mathrm{PB}=$ Proteina bruta

$\mathrm{FB}=$ Fibra bruta

$\mathrm{EE}=$ Extrato etéreo

$\mathrm{MM}=$ Motéria mineral

ENN = Extrathos näo-nitrogenados

$\mathrm{Ca}=$ Cálcio

$\mathrm{P}=$ Fóstoro

Tabela 2

Consumo de feno, concentrados, matéria seca (MS) tołal por dia, ms/100 kg de peso e MS/kg peso metabólico, nos diversos tratamentos. Pirassununga - SP, 1990.

\begin{tabular}{|c|c|c|c|c|c|c|c|c|}
\hline Tratamentos & \multicolumn{2}{|c|}{ A } & \multicolumn{2}{|c|}{ B } & \multicolumn{2}{|c|}{ C } & \multicolumn{2}{|c|}{$D$} \\
\hline N-Animal & 1150 & 1170 & 1154 & 1179 & 1165 & 1160 & 1159 & 1147 \\
\hline Feno $(\mathrm{kg} / \mathrm{d}) \mathrm{MS}$ & 1,60 & 1,60 & 2,40 & 2,40 & 2,78 & 1,52 & 3,54 & 3,86 \\
\hline Conc. $(\mathrm{kg} / \mathrm{d}) \mathrm{MS}$ & 2,40 & 2,40 & 1,60 & 1,60 & 0,69 & 0,46 & 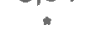 & 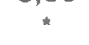 \\
\hline MS Total $(\mathrm{kg} / \mathrm{d})$ & 4,00 & 4,00 & 4,00 & 4,00 & 3,47 & 1,98 & 3,54 & 3,86 \\
\hline MS (Kg/d/100 kg) & 1,49 & 1,89 & 1,75 & 1,73 & 1,44 & 0,89 & 1,67 & 1,88 \\
\hline MS (kg/d/kg 0,75) & 0,60 & 0,72 & 0,68 & 0,67 & 0,57 & 0,34 & 0,64 & 0,071 \\
\hline P.Feno/Canc. $\%$ & 40,0 & 40,0 & 60,0 & 60,0 & 80,1 & 79,8 & 100,0 & 100,0 \\
\hline
\end{tabular}

MS = matéria seca

(") $=500 \mathrm{~g}$ de melaço $+80 \mathrm{~g}$ de uréia $+40 \mathrm{~g}$ de sulfato de cálcio

Tabela 3

Coeficientes de digestibilidade e nutrientes digestiveis totais (\%) em bovinos. Pirassununga-SP, 1990.

\begin{tabular}{c|c|c|c|c|c|c}
$\begin{array}{c}\text { Tratamento } \\
\text { Volumoso/Concentrados }\end{array}$ & MS & PB & FB & ENN & EE & NDT \\
\hline A 40/60 & 71,61 & 73,32 & 59,74 & 75,95 & 72,90 & 63,13 \\
B 60/40 & 71,43 & 78,12 & 66,56 & 73,94 & 70,84 & 62,20 \\
C 80/20 & 60,39 & 73,55 & 63,80 & 58,02 & 61,04 & 54,96 \\
D 100/0 & 62,61 & 74,34 & 65,74 & 60,93 & 63,30 \\
\hline Prob. <F & $0,005^{*}$ & 0,813 & 0,234 & $0,002^{* *}$ & $0,030^{*}$ & $0,006^{* *}$ \\
\hline
\end{tabular}

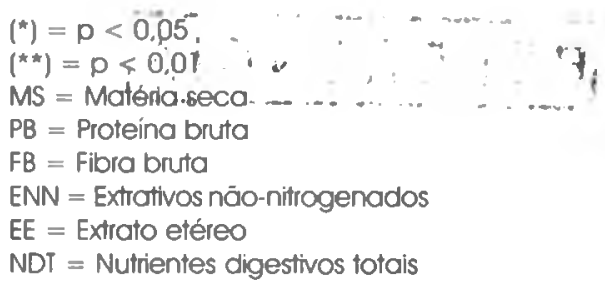




\section{CONCLUSÕES}

Com base nos resultados de digestibilidade obtidos no presente trabalho, para proporções de $40 / 60,60 / 40$, $80 / 20$ e $100 / 0$ de feno e concentrado, é possível concluir que:

1- As digestibilidades da MS, dos ENN e o teor de
NDT das dietas aumentaram à medida que os tratamentos eram constituídos de mais concentrados, sendo os melhores resultados os obtidos com proporção $40 / 60$ feno/concentrados;

2- A proteína e a fibra não foram afetadas em suas digestōes. pelos diversos tratamentos empregados.

\section{SUMMARY}

The objective of this work was to evaluate the apparent digestibility of soybean meal and of "coast-cross" hay with different levels of roughage: $A=40 \% ; B=60 \% ; C=80 \%$ and $D=100 \%$ hay on the diets. Digestion trial was runned with 8 steers, $200 \mathrm{~kg}$ average live weight, in a complete randomized design. The period of faeces collection was seven days. Digestion coefficients were: DM $71,61 \%$, $71,43 \%, 60,39 \%$ and $62,61 \% ; \mathrm{CP}=73,32 \%, 78,12 \%, 73,55 \%$ and $74,34 \% ; \mathrm{CF}=59,74 \%, 66,56 \%, 63,80 \%$ and $65,74 \% ; \mathrm{ENN}=$ $75,95 \%, 73,94 \% 58,02 \%$ and $60,93 \%$; EE $=72,90 \%, 70,84 \%, 61,04 \%$ and $63,30 \%$, for $A, B, C$ and D treatments, respectively. TDN values were: $A=63,13 \%, B=62,20 \%, C=54,96 \%$ and $D=51,28 \%$. Digestion coefficents of DM and NFE and TDN values increased, as more concentrates were employed on cattle's diets.

\section{REFERÊNCIAS BIBLIOGRÁFICAS}

I-AOAC - ASSOCIATION OF OFFICIAL AGRICLILTURAL CHEMISTS Official methods of analysis, $10 \mathrm{ed}$. Washington. AOAC, 1980. $1141 \mathrm{p}$.

2-CASTRO. T.; BERMUDE $Z$. F.F.: SANZ.ARIAS, R. Effect of roughage to concentrate ratio diet on digestibility of dry - matter and cell - wall constituents. Archivos de Zootecnia. v.40, n.146. p.85-90. 1991.

3-COLUCCI. P.E.; MACLEOD, G.K.: GROVUM, W.L.; CAHILL, L. W.; McMILLAN. 1. Comparative digestion in sheep and catte fed different forage to concentrate rations at high and low intakes. Journal of Dairy Science. v.72, n.7. p.1774-85, 1989.

4-DZHURBINEV, D.: T'ODOROU. N.: P"RVANOVA, V. Effect of additional concentrate feed on fattening of young bulls with maize silage. Zhivotnov'DniNauki. v.26, n.5, p.11-8, 1989.

5-FLACHOWSKY, G.; SCHNEIDER, M. Influence of various straw-toconcentrate ratios on in sacco dry matter degradability, feed intake and apparent digestibility in ruminants. Animal Feed Science and Technology. v.38, n.2/3. p. 199-217. 1992.

6-GOMES, F.P. Curso de estatística experimental. 11 ed., Piracicaba. SP. FEALQ-USP. 1985

7-HORN, L.H.; RAY, M.L.: NF.WMANN, A.L. Digestion and nutrient balance trials for steers. Journal of Animal Science, v.13, n.1, p.20-4, 1954.

8-KAWAS. J R : I.OPES. J.; DANELON. D.L.: LU, C.I). Influence of forage 10 concentrate ratios on intake, digestibility, chewing and milk production of dairy goats. Small Ruminant Research, v.4, n. I. p.11-8, 1991.

9-KHALILI, H.; VARVIKKO. T.; CROSSE, S. The effects of forage type and level of concentrate suplementation on food intake. diet digestibility and milk production of crossbred cows (Bos taurus $x$ Bos indicus). Animal Production. v.54. p. 183-9. 1992.

10-NRC - NATIONAL RESEARCH COUNCIL. Nutrient requirements of dairy cattle. Washington, NRC, 1989, p. 157.

II.POORE. M.H.: MOORE. J.A.; SWINGLE. R.S. Differential passage rates and digestion of neutral detergent fiber from grain and forages in 30,60 and $90 \%$ concentrate diets fed to steers, Journal Animal Science, v.68, n.9, p. 2965-73, 1990).

12-ROBINSON. P.H.; KFNNELY, J.J. Intluence of degradability of supplemental protein and time post-partum in early lactation dairy cows. 1. Rumen fermentation and milk production. Livestock Production Science. v. 28. n.2, p. $121-38,1991$

13-SCHNEIDER. B.H.; FI.ATT. W.P. The evaluation of feeds through digestibility experiments. Athens. Univ. of Georgia. 1975, 423 p.

14-UDEN, P. The effect of intake and hay: concentrate ratio upon digestibility and digesta passage. Inimal Feed Science and Technology, v. 11, n.3. p. 167 . 79. 1984 .

\section{REFERENCIA}

Recebido para aprovação: (19/05/95 Aprovado para publicação: 25/04/96 